\title{
Intracranial nonvestibular neurinomas: Young neurosurgeons' experience
}

Forhad Hossain Chowdhury, Mohammod R. Haque, Khandkar A. Kawsar, Mainul H. Sarker, Mahmudul Hasan', Atul H. Goel ${ }^{2}$

Department of Neurosurgery, Dhaka Medical College Hospital, ${ }^{1}$ Department of ENT and Head Neck Surgery, Shohid Shawrowardi Medical College and Hospital, Dhaka, Bangladesh, ${ }^{2}$ Department of Neurosurgery, Seth GS Medical College and KEM Hospital, Mumbai, Maharashtra, India

\begin{abstract}
Background and Objectives: Neurinoma arising from other than nonvestibular cranial nerves is less prevalent. Here we present our experiences regarding the clinical profile, investigations, microneurosurgical management, and the outcome of nonvestibular cranial nerve neurinomas. Materials and Methods: From January 2005 to December 2011, the recorded documents of operated nonvestibular intracranial neurinomas were retrospectively studied for clinical profile, investigations, microneurosurgical management, complications, follow-up, and outcomes. Results: The average follow-up was $\mathbf{2 4 . 5}$ months. Total number of cases was 30 , with age ranging from 9 to 60 years. Sixteen cases were males and 14 were females. Nonvestibular cranial nerve schwannomas most commonly originated from trigeminal nerve followed by glossopharyngeal+/vagus nerve. There were three abducent nerve schwannomas that are very rare. There was no trochlear nerve schwannoma. Two glossopharyngeal+/vagus nerve schwannomas extended into the neck through jugular foramen and one extended into the upper cervical spinal canal. Involved nerve dysfunction was a common clinical feature except in trigeminal neurinomas where facial pain was a common feature. Aiming for no new neurodeficit, total resection of the tumor was done in 24 cases, and near-total resection or gross total resection or subtotal resection was done in 6 cases. Preoperative symptoms improved or disappeared in 25 cases. New persistent deficit occurred in 3 cases. Two patients died postoperatively. There was no recurrence of tumor till the last follow-up. Conclusion: Nonvestibular schwannomas are far less common, but curable benign lesions. Surgical approach to the skull base and craniovertebral junction is a often complex and lengthy procedure associated with chances of significant morbidity. But early diagnosis, proper investigations, and evaluation, along with appropriate decision making and surgical planning with microsurgical techniques are the essential factors that can result in optimum outcome.
\end{abstract}

Key words: Intracranial, microneurosurgical management, neurilemmomas, neurinomas, nonvestibular, schwannomas

\section{Introduction}

Schwannomas or neurilemmomas or neurinomas are benign tumors arising from the Schwann cells of spinal, cranial, or peripheral nerves. Schwannoma can arise from any cranial nerve, including the optic nerve sheath, except the olfactory nerve ${ }^{[1,2]}$ Most common intracranial schwannomas arise from vestibular nerves. Schwannoma arising from oculomotor, trochlear, and abducent nerves are extremely rare.$^{[3]}$ Intracranial neurinomas arising

\begin{tabular}{|l|l|}
\hline \multicolumn{2}{|c|}{ Access this article online } \\
\hline Quick Response Code: & Website: \\
\hline & www.ruralneuropractice.com \\
\cline { 2 - 3 } & \\
\hline
\end{tabular}

from other cranial nerves (non vestibular) are very rare and constitute $2.9-4 \%$ of all schwannomas. ${ }^{[4]}$

Here we present our experiences regarding the clinical profile, investigations, microneurosurgical management, and outcome of nonvestibular cranial nerve neurinomas.

\section{Materials and Methods}

From January 2005 to December 2011, 246 intracranial neurinomas (including orbital neurinomas) were operated in Department of Neurosurgery, Dhaka Medical College Hospital and some private Hospital in Dhaka city. Among these, 216 were vestibular schwannomas and the remaining were nonvestibular schwannomas. Recorded documents were retrospectively studied for clinical profile, investigations, microneurosurgical management, complications, and outcomes. Postoperatively, the patients

Address for correspondence:

Dr. Forhad Hossain Chowdhury, Department of Neurosurgery, Dhaka Medical College Hospital, Dhaka, Bangladesh.

E-mail: forhadchowdhury74@yahoo.com 
were followed up clinically and radiologically at a regular interval. Postoperative computed tomography (CT) scan was performed in the immediate postoperative period. Postoperative magnetic resonance imaging (MRI)/CT scan of brain was done 3 months after the operation. MRI of brain was done 1 year after the operation and then imaging was done where recurrence was suspected on the basis of clinical symptoms. In a few instances where the patients failed to attend the scheduled follow-up, the follow-up was conducted over cellphone. Two patients were lost to follow-up since their discharge and were not included in this series.

\section{Results}

Total number of cases was 30 . Their age range was 9-60 years. Males numbered 16 years and females were 14 in number. Nonvestibular cranial nerve schwannoma most commonly originated from the trigeminal nerve followed by glossopharyngeal/vagus nerve. There were three abducent nerve schwannomas which are very rare. One abducent nerve schwannoma was associated with concurrent vestibular nerve schwannoma. In another trigeminal neurinoma, there was a concurrent opposite-sided vestibular schwannoma. Nerve distribution of nonvestibular schwannoma is shown in Table 1.

Details of all cases are summarized in Table 2 and Figures 1-9.

Both third nerve schwannomas were retro-orbital with superior orbital fissure involvement. Preoperative nerve paresis did not improve after operation. There was preoperative sixth nerve palsy in all sixth nerve schwannomas. One abducent nerve involved cavernous sinus, superior orbital fissure, and retro-orbital space. One trigeminal nerve schwannoma was from the infraorbital branch of the maxillary nerve and was completely orbital. Another trigeminal schwannoma extended into temporal fossa (TF), infratemporal fossa (ITF), and retro-orbital space. Another one extended into posterior fossa (PF), TF, and ITF. One mandibular nerve schwannoma starting from TF extended into ITF through foramen ovale. Six trigeminal

Table 1: Distribution of nonvestibular neurinomas

\begin{tabular}{lcc}
\hline Nerve & Number & Percentage \\
\hline Oculomotor & 02 & 6.66 \\
Trochlear & 00 & 00 \\
Trigeminal & 13 & 43.5 \\
Abducent & 03 & 10 \\
Facial & 02 & 6.66 \\
Glossopharyngeal+/vagus & 05 & 16.5 \\
Accessory & 02 & 6.66 \\
Hypoglossal & 03 & 10 \\
\hline
\end{tabular}

schwannomas were only in $\mathrm{PF}$, extending into petrous apex (PA). One facial nerve schwannoma arose from geniculate ganglion and the remaining were just outside the internal acoustic meatus. Two glossopharyngeal+/ vagus nerve schwannomas extended into the neck through jugular foramen (JF) and one extended into the upper cervical spinal canal. Involved nerve paresis/palsy is a common clinical picture in all nonvestibular cranial nerve schwannomas except in trigeminal nerve schwannoma where facial pain (according to the involved trunk or branch) is the most common followed by features of raised intracranial pressure (ICP). Motor weakness in trigeminal schwannoma was found only in one case. Most of the nonvestibular schwannomas were solid, iso- or hyperintense lesions that enhanced after contrast injection. Different surgical approaches were used for different schwannomas according to the site. We removed the sixth nerve schwannoma from cavernous sinus through extradural subtemporal approach. We faced minimum bleeding during tumor removal as the cavernous sinus was already filled with the tumor. In one sixth nerve schwannoma where there was a concurrent same-sided vestibular schwannoma, vestibular schwannoma was removed near totally 1 month after the removal of sixth nerve schwannoma. During the removal of large trigeminal neurinoma that extended into $\mathrm{PF}, \mathrm{TF}$, and ITF through extradural subtemporal approach, the large dural opening could not be closed, but vascularized temporal muscle and fascia (posterior part) was rerouted to close the dural gap (non-watertight) and dead space. Postoperatively we did not face any cerebrospinal fluid (CSF) leak or pseudomeningocele (surgical approach related experience). In all cases of PF tumor, we tried to preserve the petrosal vein; but in two cases, we had to coagulate the vein. In JF schwannomas (JFSs), we closed the foramen by thigh fascia lata and fat graft. In transcondylar approach, we drilled only posterior one-third of the condylar joint. In PF craniectomy, we repositioned the bone chips in all cases. In one case, there was persistent discharging sinus at the craniectomy site where re-exploration showed abnormally large amount of bone wax at the bone margin. Surgical approaches with complications are summarized in Table 3.

Total resection (TR) of the tumor was done in 24 cases, near-total resection (NTR) 1 case, gross total resection (GTR) in 2 cases, and subtotal resection (STR) was done in 3 cases. This was confirmed by postoperative MRI of the brain. One patient with STR was sent for radiotherapy (early part of the series) and another patient with STR expired early postoperatively. In the rest of the cases with STR, repeated postoperative MRI showed shrinkage of the residual tumor.

Preoperative symptoms improved or disappeared in 25 cases (out of 29). New persistent deficit occurred 
Table 2: Summery of details of all cases

\begin{tabular}{|c|c|c|c|c|c|}
\hline No. & $\begin{array}{l}\text { Age (years), sex } \\
\text { and involved nerve }\end{array}$ & Clinical features & $\begin{array}{l}\text { MRI findings of tumor } \\
\text { with site }\end{array}$ & $\begin{array}{l}\text { Surgical } \\
\text { approach }\end{array}$ & $\begin{array}{l}\text { Extent of resection, outcome, } \\
\text { and complication }\end{array}$ \\
\hline 1 & $9, \mathrm{M}, 3^{\text {rd }}$ nerve & $\begin{array}{l}\text { Proptosis, diplopia, VD, } 3^{\text {rd }} \\
\text { nerve paresis }\end{array}$ & $\begin{array}{l}\text { Solid } 2 \times 3 \mathrm{~cm}, \mathrm{RO} \text { and } \\
\text { SOF }\end{array}$ & $\begin{array}{l}\text { Lateral } \\
\text { micro-orbitotomy }\end{array}$ & $\begin{array}{l}\text { TR, frontal branch of facial } \\
\text { damage, symptoms recovered } \\
\text { with persistent paresis }\end{array}$ \\
\hline 2 & $32, F, 3^{\text {rd }}$ nerve & $\begin{array}{l}\text { Proptosis, diplopia, VD, } 3^{\text {rd }} \\
\text { nerve palsy }\end{array}$ & $\begin{array}{l}\text { Solid, } 2 \times 3 \mathrm{~cm}, \mathrm{RO} \text { and } \\
\text { SOF }\end{array}$ & Fronto-orbitotomy & NTR, $3^{\text {rd }}$ nerve palsy persisted \\
\hline 3 [Figure 1] & $28, F$, trigeminal & $\mathrm{HA}$ and $\mathrm{FP}$ & Solid, $7 \times 5 \mathrm{~cm}$ PF and TF & ST-EXD & $\begin{array}{l}\text { TR, vi palsy-transient, corneal } \\
\text { macula }\end{array}$ \\
\hline 4 & $19, \mathrm{M}$, trigeminal & $\begin{array}{l}\text { Unconscious } \\
\mathrm{H} / \mathrm{O} \mathrm{HA} \text {, vomiting, VD }\end{array}$ & $\begin{array}{l}\text { Mainly cystic, } 4 \times 4 \mathrm{~cm} \text {, in } \\
\text { PF and PA }\end{array}$ & RMRSLSC & $\begin{array}{l}\text { TR, expired from aspiration } \\
\text { pneumonia }\end{array}$ \\
\hline 5 & $52, \mathrm{M}$, trigeminal & Facial pain, fall & Solid, $5 \times 4 \mathrm{~cm}$, in PF & RMRSLSC & NTR, symptoms gone \\
\hline 6 & $55, \mathrm{~F}$, trigeminal & $\begin{array}{l}\text { Facial pain, HA, V, VD, } \\
\text { unconsciousness }\end{array}$ & $\begin{array}{l}\text { Solid+cystic, } 4 \times 2.5 \mathrm{~cm} \text {, } \\
\text { PF }\end{array}$ & RMRSLSC & TR, complete recovery \\
\hline 7 & $45, M$, trigeminal & $H A, V, V D$ & $\begin{array}{l}\text { Solid, } 4 \times 3.5 \mathrm{~cm}, \mathrm{PF} \text { and } \\
\text { PA }\end{array}$ & RMRSLSC & TR, symptoms disappeared \\
\hline 8 & 38, $M$, trigeminal & $H A, F P, V, V D$ & $\begin{array}{l}\text { Solid, } 7 \times 5 \mathrm{~cm}, \mathrm{PF} \\
\mathrm{TF} \text {, and ITF }\end{array}$ & ST-EXD & TR, vi palsy (transient) \\
\hline 9 & $28, \mathrm{~F}$, trigeminal & $\mathrm{HA}, \mathrm{V}, \mathrm{GI}$ & $\begin{array}{l}\text { Solid, } 3 \times 3 \mathrm{~cm} \text {, } \\
\text { PF and PA }\end{array}$ & RMRSLSC & TR, neuropathic keratitis \\
\hline 10 [Figure 2] & $\begin{array}{l}51, \mathrm{M} \text {, trigeminal } \\
\text { and vestibular }\end{array}$ & $\begin{array}{l}\text { FP (lower face) and } \\
\text { hearing impairment }\end{array}$ & $\begin{array}{l}\text { Solid, } 2.5 \times 3 \mathrm{~cm}, \mathrm{PF} \\
\text { and PA (right trigeminal } \\
\text { schwannoma) and } \\
\text { left }(2 \times 2.5 \mathrm{~cm}) \text { vestibular } \\
\text { schwannoma }\end{array}$ & $\begin{array}{l}\text { RMRSLSC (right } \\
\text { and left two } \\
\text { sittings) }\end{array}$ & $\begin{array}{l}\text { TR of trigeminal schwannoma } \\
\text { and near-total resection of } \\
\text { vestibular schwannoma, } \\
\text { symptoms recovered except } \\
\text { hearing }\end{array}$ \\
\hline 11 & $46, F$, trigeminal & Headache, facial pain & $\begin{array}{l}\text { Solid, } 2 \times 2 \mathrm{~cm}, \mathrm{PF} \text { and } \\
\text { PA }\end{array}$ & RMRSLSC & TR, symptoms recovered \\
\hline 12 & $36, \mathrm{M}$, trigeminal & $\begin{array}{l}\mathrm{HA}, \mathrm{FP} \text {, mastication } \\
\text { weakness }\end{array}$ & Solid, $3 \times 3 \mathrm{~cm}$, TF & $\begin{array}{l}\text { ST-EXD, } \\
\text { radiotherapy }\end{array}$ & STR, symptoms recovered \\
\hline 13 [Figure 3] & $17, \mathrm{~F}$, trigeminal & FP (lower) & $\begin{array}{l}\text { Solid } 2 \times 3 \mathrm{~cm} \mathrm{TF}, \mathrm{FO} \text {, } \\
\text { and ITF }\end{array}$ & ST-EXD & TR, symptoms disappeared \\
\hline 14 & $\begin{array}{l}34, F \text {, trigeminal } \\
\text { (maxillary) }\end{array}$ & $\mathrm{HA}, \mathrm{FP}(\mathrm{mid})$ & $\begin{array}{l}\text { Solid, } 3 \times 4 \mathrm{~cm} \text {, TF and } \\
\text { PF }\end{array}$ & ST-EXD & TR, symptoms disappeared \\
\hline 15 & $\begin{array}{l}35, \mathrm{~F} \text {, trigeminal } \\
\text { (infraorbital) }\end{array}$ & $\begin{array}{l}\text { Pain, proptosis, } \\
\text { inferolateral orbital swelling }\end{array}$ & $\begin{array}{l}\text { Solid, } 2 \times 1.5 \mathrm{~cm} \text {, } \\
\text { inferolateral orbit }\end{array}$ & $\begin{array}{l}\text { Transconjunctival } \\
\text { removal }\end{array}$ & TR, symptoms recovered \\
\hline 16 & 38, F, vi nerve & Diplopia, vi palsy & Solid, $2 \times 1.5 \mathrm{~cm}$, TF (CS) & ST-EXD & TR, vi palsy persisted \\
\hline 17 [Figure 4] & $\begin{array}{l}30, \mathrm{M}, \mathrm{vi} \text { and viii } \\
\text { nerves }\end{array}$ & $\begin{array}{l}\text { HA, eye ache, vi palsy, } \\
\text { hearing impairment }\end{array}$ & $\begin{array}{l}\text { Sold, } 3 \times 2.5 \mathrm{~cm}, \mathrm{TF}(\mathrm{CS}) \\
\text { and another } 1 \times 1.5 \mathrm{~cm} \\
\text { vestibular schwannoma } \\
\text { at CPA }\end{array}$ & $\begin{array}{l}\text { ST-EXD (vi) and } \\
\text { left RMRSLSC } \\
\text { (viii) (two sittings) }\end{array}$ & $\begin{array}{l}\text { TR, vi palsy persisted, hearing } \\
\text { impairment persisted }\end{array}$ \\
\hline 18 & $60, \mathrm{M}$, vi nerve & Proptosis, vi palsy & $\begin{array}{l}\text { Solid, } 5 \times 2.5 \mathrm{~cm} \text {, } \\
\text { TF (CS), SOF, and RO }\end{array}$ & ST-EXD & TR, vi palsy persisted \\
\hline 19 [Figure 5] & $45, M$, vii nerve & $\begin{array}{l}\text { Rt facial paresis (B and } \mathrm{H} \\
\text { Grade- } 3+\text { ), hearing intact }\end{array}$ & Solid, $1 \times 1.5 \mathrm{~cm}, \mathrm{CPA}$ & RMRSLSC & $\begin{array}{l}\text { TR, initial postoperative } \\
\text { deterioration, then improvement } \\
\text { up to preoperative level }\end{array}$ \\
\hline 20 & $\begin{array}{l}21, \mathrm{M}, \text { vii and } \\
\text { greater petrosal } \\
\text { nerves }\end{array}$ & $\begin{array}{l}\mathrm{Lt} \text { facial paresis (B and } \mathrm{H} \\
\text { Grade- } 3+\text { ), xerophthalmia }\end{array}$ & $\begin{array}{l}\text { Solid, } 1.5 \times 1.5 \mathrm{~cm} \text {, facial } \\
\text { canal, TF }\end{array}$ & ST-EXD & $\begin{array}{l}\text { TR, initial postoperative } \\
\text { deterioration, then improvement } \\
\text { up to preoperative level }\end{array}$ \\
\hline 21 [Figure 6] & $\begin{array}{l}30, M, i x / x \text { nerve } \\
\text { (JFS) }\end{array}$ & $\begin{array}{l}\mathrm{HA}, \mathrm{V}, \mathrm{VD}, \mathrm{GI} \text {, hearing } \\
\text { impairment, palatal and } \\
\text { uvular deviation, xi, xii } \\
\text { palsy }\end{array}$ & $\begin{array}{l}\text { Solid, } 9 \times 4 \mathrm{~cm}, \mathrm{PF}, \mathrm{JF} \\
\text { cervical }\end{array}$ & $\begin{array}{l}\text { RMRSLS and } \\
\text { transmastoid high } \\
\text { cervical }\end{array}$ & GTR \\
\hline 22 & $\begin{array}{l}28, M, i x / x \text { nerve } \\
\text { (JFS) }\end{array}$ & $\begin{array}{l}\mathrm{HA}, \mathrm{V}, \mathrm{VD}, \mathrm{GI} \text {, hearing } \\
\text { impairment, palatal and } \\
\text { uvular deviation }\end{array}$ & $\begin{array}{l}\text { Solid, } 8 \times 4 \mathrm{~cm}, \mathrm{PF}, \mathrm{JF} \\
\text { cervical }\end{array}$ & $\begin{array}{l}\text { RMRSLS } \\
\text { candtransmastoid } \\
\text { high cervical }\end{array}$ & $\begin{array}{l}\text { GTR, swallowing } \\
\text { difficulty (transient) }\end{array}$ \\
\hline 23 & $25, M, i x / x$ nerve & $\begin{array}{l}\text { Asymptomatic, uvular } \\
\text { deviation }\end{array}$ & $\begin{array}{l}\text { Solid, Lt CPA, FM, and } \\
\text { cervical spinal canal }\end{array}$ & $\begin{array}{l}\text { RMRSLSC } \\
\text { with C1 and C2 } \\
\text { laminectomy }\end{array}$ & $\begin{array}{l}\text { Subtotal resection, transient } \\
\text { hemiplegia, tracheostomy, } \\
\text { ventilation, long persistent } \\
\text { swallowing difficulty (then } \\
\text { recovered), stiff TM joint }\end{array}$ \\
\hline 24 & $35, F$, ix nerve & $\mathrm{HA}, \mathrm{V}, \mathrm{VD}, \mathrm{GI}$ & Solid, $3 \times 3 \mathrm{~cm}$, Lt CPA & RMRSLSC & $\begin{array}{l}\text { TR (initial wrong-sided } \\
\text { craniectomy) }\end{array}$ \\
\hline
\end{tabular}

Contd... 
Table 2: Contd...

\begin{tabular}{|c|c|c|c|c|c|}
\hline No. & $\begin{array}{l}\text { Age (years), sex } \\
\text { and involved nerve }\end{array}$ & Clinical features & $\begin{array}{l}\text { MRI findings of tumor } \\
\text { with site }\end{array}$ & $\begin{array}{l}\text { Surgical } \\
\text { approach }\end{array}$ & $\begin{array}{l}\text { Extent of resection, outcome } \\
\text { and complication }\end{array}$ \\
\hline 25 [Figure 7] & $56, F$, ix nerve & $\begin{array}{l}\mathrm{HA}, \mathrm{V}, \mathrm{VD}, \mathrm{GI}, \text { nasal } \\
\text { regurgitation }\end{array}$ & Solid, $3 \times 3 \mathrm{~cm}$, Rt CPA & RMRSLSC & $\begin{array}{l}\text { TR, complete resection, } \\
\text { dysphagia (transient), } \\
\text { persistent discharging } \\
\text { sinus (re-exploration needed) }\end{array}$ \\
\hline 26 [Figure 8] & 38, $\mathrm{M}$, xi nerve & $\begin{array}{l}\text { Neck pain, quadriparesis, } \\
\text { trapezius, and SM } \\
\text { weakness }\end{array}$ & $\begin{array}{l}\text { Solid, } 3 \times 4 \mathrm{~cm} \text {, FM, and } \\
\text { PF }\end{array}$ & $\begin{array}{l}\text { Lt suboccipital } \\
\text { craniotomy with } \\
\text { C1 posterior arch } \\
\text { removal }\end{array}$ & $T R$, full recovery \\
\hline 27 & $52, F$, xi nerve & $\begin{array}{l}\text { Neck pain, occipital HA, } \\
\text { quadriparesis, Lt SM and } \\
\text { trapezius atrophy }\end{array}$ & $\begin{array}{l}\text { Solid, } 3 \times 3 \mathrm{~cm}, \mathrm{FM} \text {, } \\
\text { upper cervical, PF }\end{array}$ & $\begin{array}{l}\text { Lt suboccipital } \\
\text { craniotomy with } \\
\text { C1 posterior arch } \\
\text { removal }\end{array}$ & $\begin{array}{l}\text { TR, recovery except SM and } \\
\text { trapezius weakness }\end{array}$ \\
\hline 28 & 40, M, xii nerve & Recurrent xii palsy & $\begin{array}{l}\text { Solid, } 1 \times 1.5 \mathrm{~cm}, \mathrm{Rt} \text { PF } \\
\text { and hypoglossal canal }\end{array}$ & $\begin{array}{l}\text { RMRSLSC, } \\
\text { transcondylar } \\
\text { approach }\end{array}$ & $\begin{array}{l}\text { TR, hypoglossal nerve function } \\
\text { recovered }\end{array}$ \\
\hline 29 & $44, \mathrm{~F}$, xii nerve & $\begin{array}{l}\text { HA, V, VD, GI, Lt } \\
\text { hypoglossal palsy }\end{array}$ & $\begin{array}{l}4 \times 3 \mathrm{~cm}, \mathrm{Lt} P F \text { and } \\
\text { hypoglossal canal }\end{array}$ & RMRSLSC & STR, expired on third POD \\
\hline 30 [Figure 9] & $35, F$, xii, nerve & $\begin{array}{l}\text { HA, V, VD, GI, Rt } \\
\text { hypoglossal palsy }\end{array}$ & Solid, $3 \times 4 \mathrm{~cm}, \mathrm{PF}$ & RMRSLSC & $\begin{array}{l}\text { TR, cured but hypoglossal } \\
\text { palsy persisted }\end{array}$ \\
\hline
\end{tabular}

F: Female, M: Male, Rt: Right, Lt: Left, HA: Headache, V: Vomiting, VD: Visual disturbance, Gl: Gait instability, FP: Facial pain, RO: Retro-orbital, SOF: Superior orbital fissure, TR: Total resection, NTR: Near-total resection, GTR: Gross total resection, STR: Subtotal resection, TF: Temporal fossa, CS: Cavernous sinus, JF: Jugular foramen, JFS: Jugular foramen schwannoma, ITF: Infratemporal fossa, PA: Petrous apex, PF: Posterior fossa, CPA: Cerebellopontine angle, FM: Foramen magnum, RMRSLSC: Retromastoid retrosigmoid lateral suboccipital craniectomy, ST-EXD: Subtemporal extradural approach, SM: Sternomastoid, TM: Temporomandibular, POD: Postoperative day, MRI: Magnetic resonance imaging

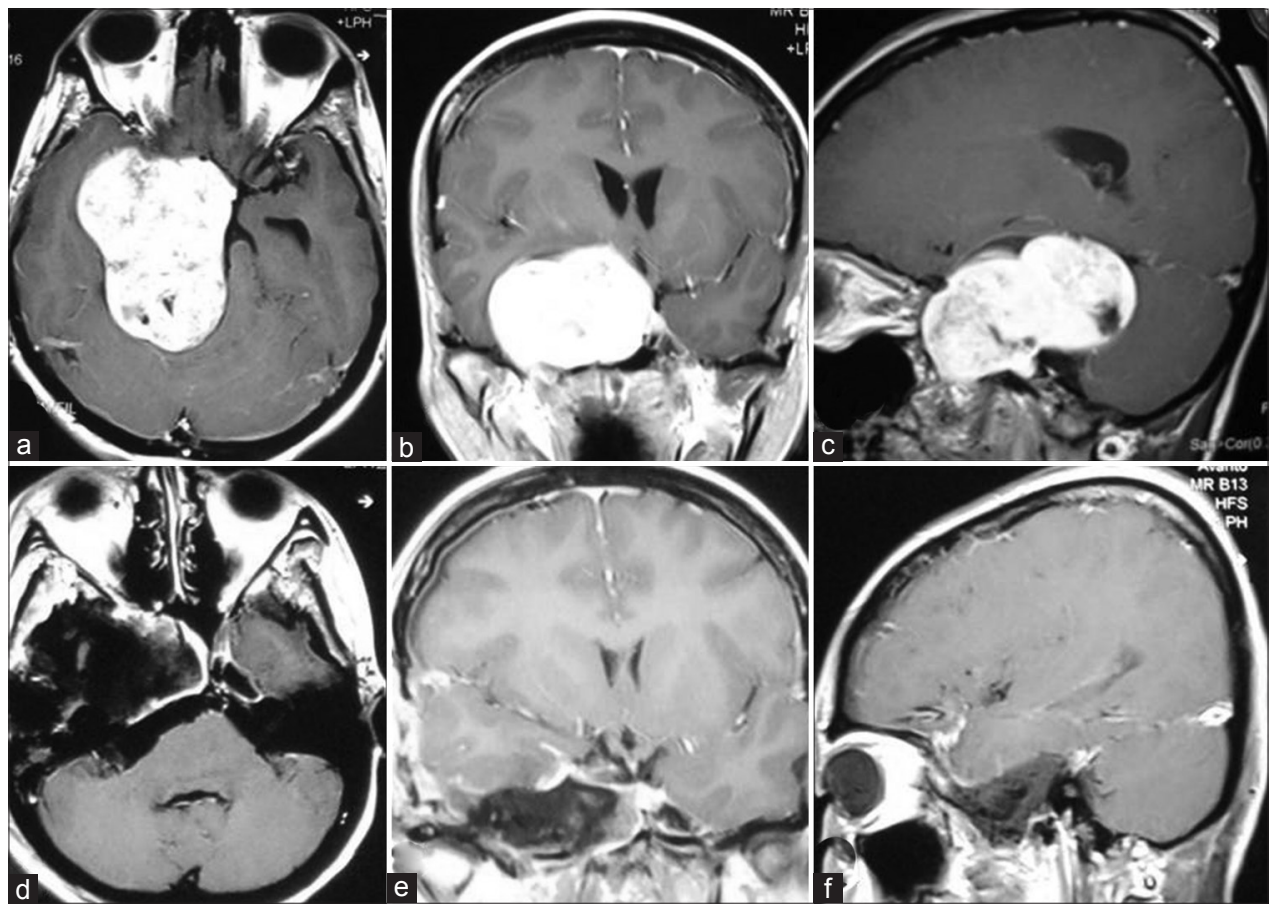

Figure 1: (a-c) Preoperative MRI of brain showing right-sided huge trigeminal schwannoma (axial, coronal, and sagittal views sequentially). (d-f) Postoperative MRI of brain showing the complete removal of tumor (axial, coronal, and sagittal views sequentially)

in three cases (dysphagia, corneal macula, and frontal branch of facial nerve deficit). Preoperative motor deficit occurred in 13 cases (except ix/x nerve schwannomas) and it improved in two cases (hypoglossal and accessory nerve schwannoma). Motor deficit persisted similar to the preoperative condition in 10 cases (one patient died). Among the patients with ix $+/ x$ nerve schwannomas, one patient had preoperative nasal regurgitation that recovered postoperatively. In the remaining cases, there was preoperative compensated nerve dysfunction where one patient developed new dysphagia postoperatively.

Two patients died postoperatively in this series. One patient with PF trigeminal nerve schwannoma developed 


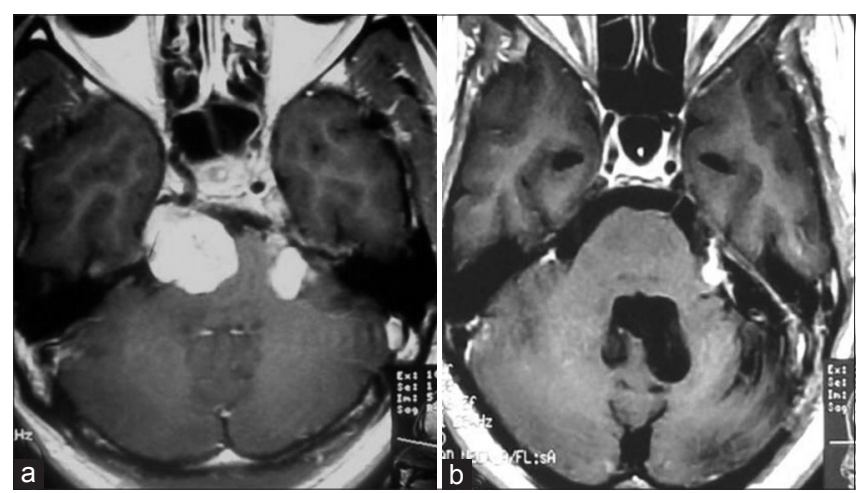

Figure 2: (a) Preoperative MRI of brain axial section showing right-sided trigeminal neurinoma and left-sided vestibular neurinoma. (b) Postoperative MRI of brain axial section showing complete removal of trigeminal neurinoma (right) and near-total removal of vestibular neurinoma (left)

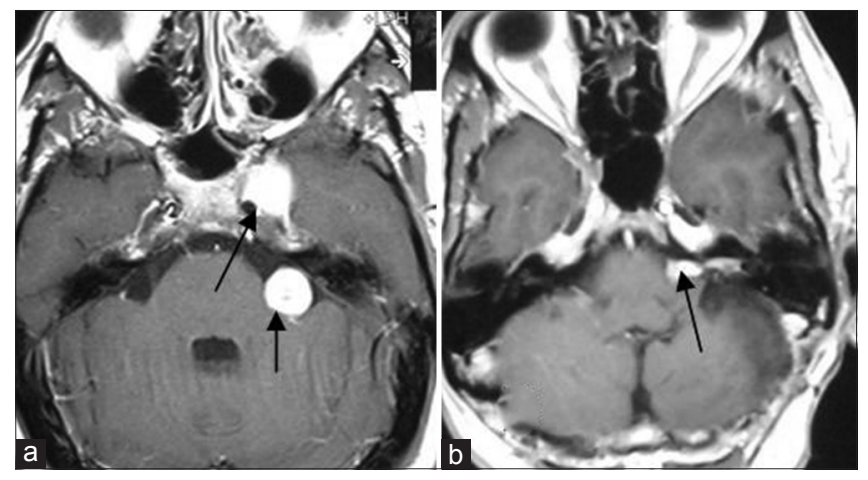

Figure 4: (a) Preoperative MRI of brain axial section showing left-sided cavernous sinus sixth nerve schwannoma and left-sided vestibular nerve schwannoma (arrows marked). (b) Postoperative MRI of brain axial section showing complete removal of sixth nerve schwannoma and near-total removal of vestibular schwannoma (arrow marked)

aspiration pneumonia and died and another patient with large hypoglossal schwannoma expired suddenly on the second postoperative day. One patient developed early postoperative hemiplegia, respiratory difficulty, and swallowing difficulty in a huge preoperatively asymptomatic glossopharyngeal or vagal schwannoma for which he had to stay in the intensive care unit (ICU) for a long time. By the end of 6 months after the operation, he recovered from hemiplegia and respiratory difficulty, but there was mild to moderate persistent dysphagia. He also had stiff temporo-mandibular joint. Wrong-sided craniectomy was done in a patient with $\mathrm{ix} / \mathrm{x}$ nerve schwannoma. There was no recurrence (clinical or radiological) of tumor till the last follow-up.

\section{Representative cases}

\section{Abducent nerve schwannoma}

This case is presented in Table 2 (No. 17) and Figure 4.

A30-year-old male presented with left-sided headache, eye ache, and gradual hearing loss which he had been suffering

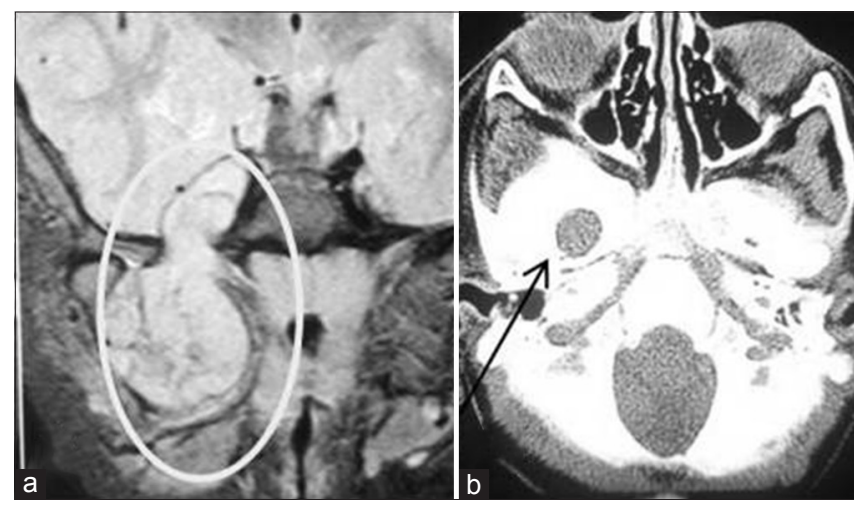

Figure 3: (a) Magnetic resonance imaging of brain coronal view showing trigeminal schwannoma (inside the ellipse) (right mandibular division) coming out into infratemporal fossa through foramen ovale. (b) Computed tomography scan of skull base (bone window) showing dilated foramen ovale (arrow indicated) on the right side

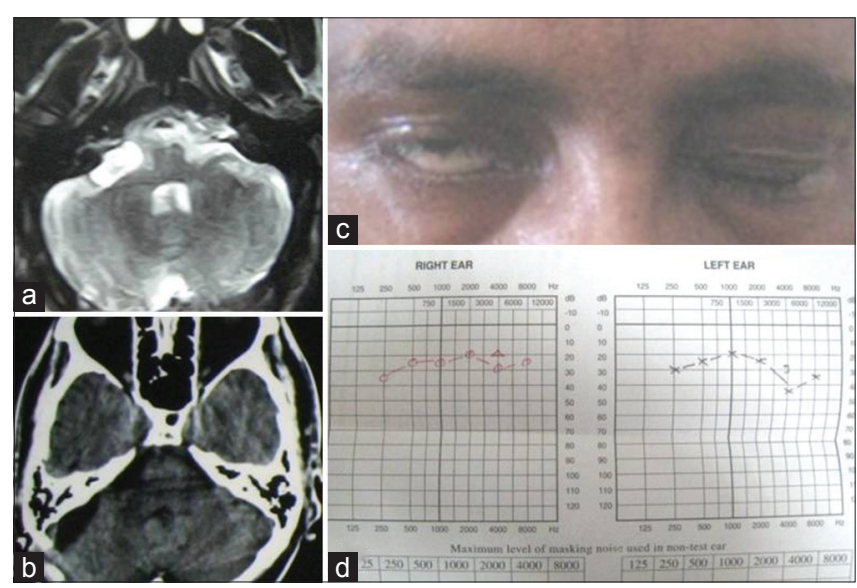

Figure 5: (a) Preoperative MRI of brain axial section (T2W image) showing right cerebellopontine angle facial nerve schwannoma. (b) Postoperative contrast CT scan axial section showing complete removal of schwannoma. (c) Preoperative facial nerve paresis. (d) Preoperative pure tone audiometry showing bilateral normal hearing

from for the last 2.5 years. He had no complaints of diplopia or visual disturbance. There was paresis of left sixth cranial nerve. He also had moderate sensori-neuronal hearing loss on the left side. Stigmata of neurofibromatosis were absent. MRI of brain showed a contrast-enhancing $3 \times 2.5 \times 2 \mathrm{~cm}$ lesion in the left cavernous sinus and a $1.5 \times 1.5 \times 1 \mathrm{~cm}$ lesion in the left cerebellopontine angle which are suggestive of abducent and acoustic nerve schwannoma, respectively. We decided to follow-up the acoustic schwannoma and operate the sixth nerve schwannoma. But the patient wanted operation for both tumors. So, we decided to operate on both tumors in two sittings. In the first operation, through left subtemporal extradural approach, we landed on the cavernous sinus tumor between the ophthalmic and trochlear nerves. As the cavernous sinus was filled up with tumor, bleeding was minimum. Tumor resected completely with preservation of the sixth nerve. Postoperatively the patient's sixth nerve paresis worsened, but improved 


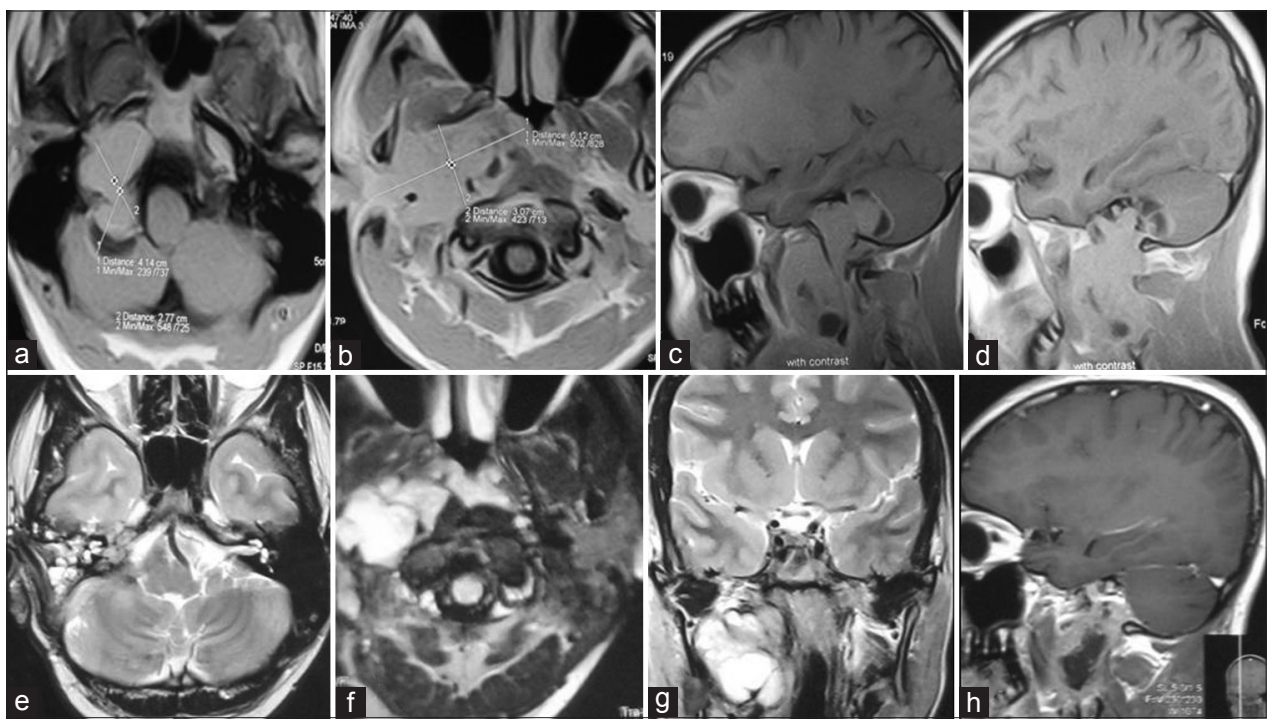

Figure 6: Preoperative MRI of brain and neck (T1W images). (a and b) Axial view and (c and d) Sagittal view showing very large right jugular foramen schwannoma (JFS) extending from posterior cranial fossa to neck (up to common carotid artery bifurcation). Postoperative MRI of brain and neck (e and f) Axial T2W images. (g) Coronal T2W image and (h) sagittal contrast image showing complete removal of intracranial portion of JFS and subtotal resection of neck portion of tumor with grafted fat in tumor dead space

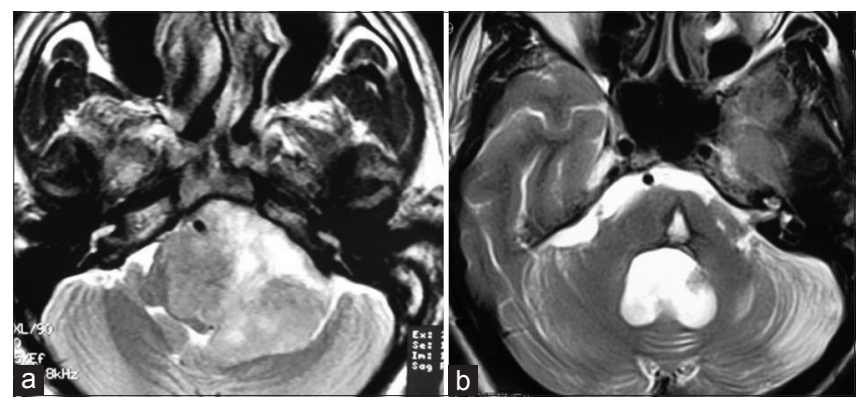

Figure 7: (a) Preoperative MRI of brain T2W axial image showing leftsided glossopharyngeal/vagal schwannoma. (b) Postoperative MRI of brain T2W axial image showing complete removal of tumor

up to preoperative level at the end of 2 months after the operation. Two and half months after the operation, we removed the acoustic neurinoma near totally through left retrosigmoid retromastoid lateral suboccipital craniectomy. Histopathologic report confirmed schwannoma in both tumors. Postoperative MRI of brain done 3 months after the second operation showed complete excision of abducent nerve schwannoma and near-total excision of acoustic schwannoma.

\section{Facial nerve schwannoma (with greater petrosal nerve)}

This case is presented in Table 2 (No. 19) and Figure 5.

A 45-year-old male presented with right facial paresis. His neurological status was normal, including hearing, except for right-sided lower motor type of facial paresis ( $\mathrm{B}$ and $\mathrm{H}$ grade 3 ). MRI of brain showed a $1 \times 1.5 \mathrm{~cm}$ contrast-enhancing hyperintense lesion in the right cerebellopontine angle. Pure tone audiometry showed bilateral intact hearing. The lesion was removed

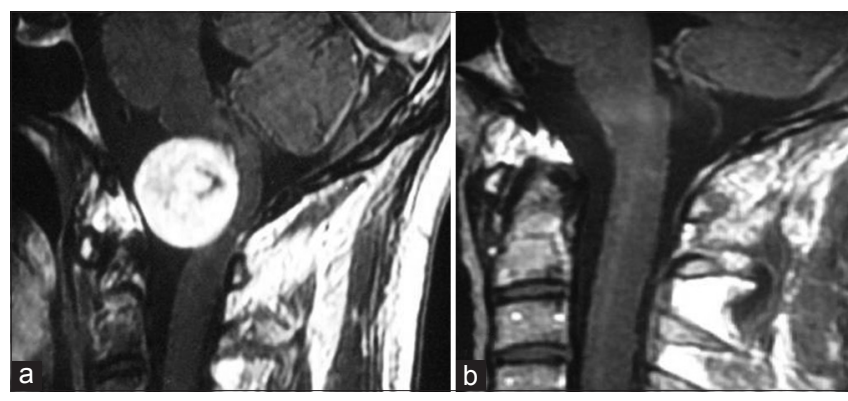

Figure 8: (a) Preoperative MRI of brain contrast sagittal view showing craniovertebral (CV) junction accessory nerve schwannoma. (b) Postoperative MRI of brain contrast sagittal view showing complete removal of tumor

totally through right retrosigmoid lateral suboccipital craniectomy. Histopathologic examination revealed schwannoma. Postoperatively the patient's right facial nerve function was stable, but did not improve till the last follow-up (13 months after the operation). Postoperative CT scan that was taken 3 months after the operation revealed no residual tumor or recurrence.

\section{JFS (ix/x nerve schwannoma)}

This case is presented in Table 2 (No. 21) and Figure 6.

A 30-year-old male presented with gradually increasing headache, vomiting, visual disturbance, vertigo, and instability during walking with a tendency to fall to the right, which he had been having for $1 \frac{1}{2}$ years. He also complained of suffering from hearing loss on the right for the last 6 months. He had no complaints regarding swallowing difficulty, nasal regurgitation, hoarseness of voice, and weakness of limbs, tongue, neck, or shoulder, but there was hearing loss and $i x, x, x i$, and 
xii nerve palsy on the right side. There was atrophy of sternocleidomastoid muscle and trapezius muscle on the right side. Right-sided cerebellar signs were positive with bilateral papilloedema. MRI of brain and neck showed isointense tumor in PF (compressing cerebellum and brain stem), JF, and neck that enhanced with contrast. CT scan showed enlargement of JF with the above-mentioned extension of tumor. Cerebral digital subtraction angiography (DSA) showed normal arterial, capillary, and venous phases including bilateral symmetrical normal sigmoid and internal jugular vein. Right-sided external carotid artery shoot showed prominent occipital and posterior auricular artery. Pure tone audiometry (PTA)

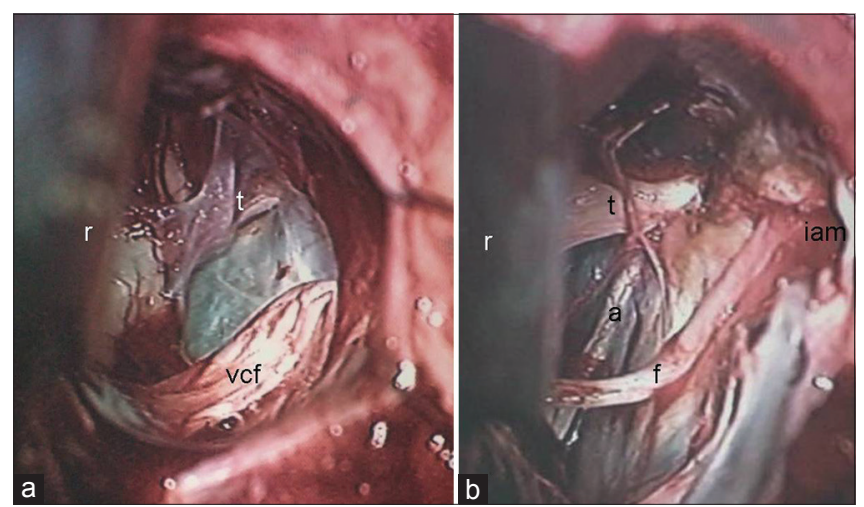

Figure 9: Comparative picture of operative views of $\mathrm{CP}$ angle after complete removal of (a) nonvestibular and (b) vestibular schwannomas. r: Cerebellar retractor; vcf: Vestibulo-chochlear-facial nerves complex; t: Trigeminal nerve; a: Abducent nerve; f: Facial nerve; iam: Internal acoustic meatus (drilled) showed neuronal hearing loss on the right side. The tumor was removed near totally through combined retrosigmoid suboccipital craniectomy and transmastoid high cervical JF approach with anterior-superio-medial mobilization of facial nerve, preservation of labyrinth, and obliteration of middle ear cavity. All cranial nerves were tried to be preserved by intracapsular removal of the tumor in neck. JF, middle ear cavity, and mastoid-petrosal areas were packed with thigh fat and mobilized vascularized posterior part of the temporalis muscle. External auditory meatus was obliterated. Postoperatively the patient recovered uneventfully, except for mild paresis of right-sided facial nerve that recovered by 12 weeks. Histopathology confirmed JFS. MRI taken 3 months after the operation showed small residual tumor at PF and fat in JF, middle ear cavity, and neck.

\section{Discussion}

Schwannomas account for $8.5 \%$ of all intracranial tumors and more than $90 \%$ of the tumors originate from the eighth cranial nerve. ${ }^{[5]}$ Cranial nerve tumors are usually rare and are schwannomas. ${ }^{[1]}$ Schwannoma can arise from any cranial nerve, including optic nerve sheath, except the olfactory nerve. ${ }^{[1,2]}$ Schwannoma arising from oculomotor, trochlear, and abducent nerves is extremely rare. ${ }^{[3]}$ Schwannomas usually occur in the sensory nerve. Schwannomas of motor nerve are very rare without neurofibromatosis. ${ }^{[6]}$ Schwannomas of the

Table 3: Surgical approaches with complications

\begin{tabular}{|c|c|c|c|}
\hline Nerve schwannoma & Surgical approach & Number & Complications \\
\hline \multirow[t]{2}{*}{ Oculomotor } & Orbitofrontal craniotomy & 1 & Frontal branch of facial nerve deficit \\
\hline & Lateral microorbitomy & 1 & Loss of papillary light reaction \\
\hline \multirow[t]{4}{*}{ Trigeminal } & Subtemporal extradural approach (ST-EXD) & & Transient vi palsy: 1 \\
\hline & Retromastoid retrosigmoid lateral suboccipital & & Corneal keratitis: 1 \\
\hline & craniectomy (RMRSLSC) & & Corneal macula: 1 \\
\hline & & & Death: 1 \\
\hline Abducent & ST-EXD & 3 & No new deficit \\
\hline \multirow[t]{2}{*}{ Facial } & RMRSLSC & 1 & No new deficit \\
\hline & ST-EXD & 1 & \\
\hline \multirow{6}{*}{$\begin{array}{l}\text { Glossopharyngeal+/ } \\
\text { vagus }\end{array}$} & RMRSLS candtransmastoid high cervical & 2 & Wrong-sided craniotomy: 1 \\
\hline & & & Transient dysphagia: 2 \\
\hline & RMRSLSC with C1 and C2 laminectomy & 1 & Persistent discharging sinus \\
\hline & RMRSLSC & 2 & (exploration needed): 1 \\
\hline & & & $\begin{array}{l}\text { Transient hemiplegia, } \\
\text { t racheostomy, ventilation, long } \\
\text { persistent swallowing difficulty (then } \\
\text { recovered) }\end{array}$ \\
\hline & & & Stiff TM joint: 1 \\
\hline Accessory & Suboccipital craniotomy with $\mathrm{C} 1$ posterior arch removal & 2 & No new deficit \\
\hline \multirow[t]{2}{*}{ Hypoglossal } & RMRSLSC with transcondylar approach & 1 & \multirow{2}{*}{$\begin{array}{l}\text { Suddenly expired on third } \\
\text { postoperative day: } 1\end{array}$} \\
\hline & RMRSLSC & 2 & \\
\hline
\end{tabular}


ocular motor cranial nerves are rare in patients without neurofibromatosis. ${ }^{[7]}$

\section{Oculomotor nerve schwannoma}

The first case report of oculomotor schwannoma was by Kovacs. ${ }^{[8]}$ There have been about 40 cases of oculomotor schwannoma reported in the literature. Most of the cases have oculomotor nerve deficit before surgery. Extent of resection varies from partial to total tumor removal. Where tumors were relatively large, postoperative oculomotor nerve palsy was almost always the result. ${ }^{[9-11]}$ Treatment of large oculomotor nerve schwannoma with mass effect to the surrounding structure is surgical resection, but that of small tumors is still controversial. ${ }^{[6]}$

\section{Trochlear nerve schwannoma}

Less than 50 cases of trochlear nerve schwannomas have been reported in the literature and usually occur in middle-aged women. ${ }^{[12]}$ Celli et al. ${ }^{[13]}$ suggested that the combination of hemiparesis, cerebellar ataxia, and sensory findings with an extra-axial mass at the tentorial notch was more indicative of fourth nerve schwannoma than the presence of a fourth nerve palsy. ${ }^{[12,13]}$ However, more recent evidence suggests otherwise. Fourth nerve palsy with diplopia is one of the common presenting symptoms. ${ }^{[13,14]}$ The most common location for trochlear schwannomas is cisternal and MRI is the gold standard for detection. ${ }^{[7,12-14]}$ In small fourth nerve schwannoma, surgical resection will almost always cause a permanent fourth nerve paralysis. ${ }^{[7,13,14]}$ Most patients with diplopia and benign fourth nerve lesions typical of trochlear nerve schwannoma can manage with prism spectacles or no treatment at all. But in our series, we did not experience any trochlear nerve schwannoma.

\section{Trigeminal nerve schwannoma}

Trigeminal neurinomas are relatively rare tumors and represent $0.2 \%$ of all intracranial tumors. ${ }^{[15-17]}$ They usually arise from the Schwann cells of the sensory root and can originate in any section of the fifth cranial nerve and, correspondingly, a variety of symptoms and signs may develop. ${ }^{[16-19]}$ The age of presentation may very widely. Clinically there is usually paresthesia or numbness, often in more than one division of the nerve. Severe or neuralgic pain is uncommon. Wasting of the temporalis and pterygoid muscles is not uncommon. The corneal reflex is usually depressed or absent. There may be symptoms of involvement of adjacent cranial nerves in the cavernous sinus and in the cerebellopontine angle. The large tumor size is also responsible for the relatively infrequently encountered symptoms of increased ICP like those of some cases of our series. The unusual symptom of pathological laughter can rarely be observed in case of large, dumbbell-shaped tumors. ${ }^{[18,19]}$
Erosion of the PA, as noted on plain X-rays or CT scans, is usually uniformly observed for larger tumors, and this finding is of diagnostic significance. ${ }^{[18,19]}$ Lesions are usually isodense on unenhanced CT, but may reveal variable attenuation. There is usually homogenous enhancement with contrast. ${ }^{[11]}$ MRI is quite useful in the differential diagnosis of primary tumors of the trigeminal nerve and Meckel's cave and in the evaluation of tumor involvement for preoperative planning. ${ }^{[17,19]}$ $\mathrm{CT}$ of the skull base may show the grossly enlarged foramen ovale ${ }^{[17,18]}$ which we found in one of our cases [Figure 3]. The characteristic anatomical location, extent, and signal characteristics make the diagnosis of trigeminal nerve schwannoma almost certain. ${ }^{[18,20]}$ The occurrence of deaths or major surgical complications with radical removal of trigeminal schwannoma is very low. ${ }^{[19]}$ One patient with trigeminal neurinoma who presented to us in an unconscious state developed postoperative aspiration pneumonia and expired. In a classic series of 44 patients reported by Dolenc, TR was achieved in $100 \%$ of the patients, including five who had undergone incomplete resection elsewhere and underwent another surgery to excise the remaining tumor. ${ }^{[20]}$ The authors recommend an epidural approach to schwannomas originating in the fifth cranial nerve peripherally to the Gasserian ganglion and either an epidural-transdural or an epidural transduraltranspetrous approach to the lesions originating in the Gasserian ganglion or in the root of the fifth nerve. ${ }^{[20]}$ The recurrence rate for cases with partial resection is relatively higher for trigeminal neuromas, compared with acoustic neuromas. ${ }^{[21]}$ Konovalov et al., ${ }^{[17]}$ on the basis of a comparatively larger experience, highlight some important points for trigeminal neuroma surgery as follows: (1) These tumors are usually well separated from the cavernous sinus and the carotid artery, which facilitates their radical removal. (2) Usually the tumor does not completely destroy the trigeminal nerve, and some of its fibers can be preserved (preservation of the first trigeminal nerve division, if possible, is especially important). (3) The basal extradural approach (which the authors call "interdural") is an effective way to reach and remove small and medium-sized trigeminal tumors. Tumors may spread along the nerve division, far from the Meckel's cavity, and other approaches may be necessary for their removal. In every case, selection of an appropriate approach should be strictly individualized. ${ }^{[17]}$ Retrosigmoid approach, lateral basal subtemporal approach, ${ }^{[18,19]}$ subtemporal transtentorial approach, ${ }^{[16,18-20]}$ combined (retrosigmoid with subtemporal transtentorial) approach, ${ }^{[16,20]}$ frontotemporal extradural temporopolar approach, ${ }^{[4,7,14,22]}$ and combined petrosal approach ${ }^{[19,20]}$ can be used for removal of tumor. In our cases, we only used 
retrosigmoid approach or lateral basal subtemporal approach.

\section{Abducent nerve schwannoma}

Only a few cases of sixth nerve schwannoma have been reported. Abducent nerve schwannoma is extremely rare except in neurofibromatosis. ${ }^{[1]}$ This type of schwannoma is common in the middle decades of life and it has a female preponderance. ${ }^{[1,3,23]}$ Tung et al..$^{[23]}$ classified abducent nerve schwannoma into two types: type 1 tumor originating from cavernous segment and type 2 tumor originating from precavernous segment (prepontine region). The patients with precavernous segment schwannoma commonly present with headache, diplopia, vi nerve palsy in cavernous segments involving tumors and headache, cranial nerve dysfunction ( $\mathrm{v}$, vi, vii, and viii), and long tract signs including hydrocephalus. ${ }^{[1,23]}$ Obviously proptosis is one of the important clinical features in post cavernous segment tumor. Contrast-enhancing MRI of brain is the most appropriate investigation for diagnosing and planning of surgery. ${ }^{[1,4]}$ Surgical approaches for prepontine schwannoma are lateral suboccipital, anterior transpetrosal \& subtemporal transtentorial approach where as subtemporal or frontotemporal extradural approach for cavernous segment schwannoma. ${ }^{[1]}$ Frontotemporal craniotomy with orbitotomy is needed for post cavernous segment schwannoma. In all cases, cranial nerve preservation remains a challenge for the surgeon. We used peroperative lumbar CSF drain for brain relaxation in our cases. In all three cases, we found that surgery in cavernous sinus for schwannoma was usually not associated with much bleeding.

\section{Facial nerve schwannoma}

Among the facial nerve schwannoma cases, the majority of patients have intratemporal tumors, with the remaining being evenly divided between intracranial and extratemporal disease. Since the first case report published in 1930, many authors have written about schwannomas of the facial nerve, usually reporting single or, at the most, a few cases. However, several larger series have been reported ${ }^{[24-27]}$ that have answered many questions about the presenting symptoms, diagnosis, and treatment of facial nerve schwannomas. The presenting symptoms are of three major types: (1) Facial palsy or paresis, (2) otologic symptoms, and (3) parotid masses resulting according to the location of tumor. ${ }^{[2,25]}$ Facial weakness, when present, may be partial or complete and may be of sudden or gradual onset. There is a high correlation between facial dysfunction and intratemporal tumor location. This association is easily explained by tumor compression of the facial nerve in the unyielding fallopian canal. Otologic problems such as neurosensory hearing loss, tinnitus, and vertigo were confined to the intracranial tumor patients. The nonspecific presentation of intracranial facial nerve schwannoma certainly makes preoperative diagnosis difficult. ${ }^{[2,27,28]}$ Accurate preoperative diagnosis of facial nerve schwannoma is important in order to advise the patient properly and plan the surgical approach. Unfortunately, it is also one of the most difficult aspects of managing patients with facial nerve schwannoma. Particularly challenging is the differentiation of intracranial facial nerve schwannomas from acoustic schwannomas. Many diagnostic tests have been recommended, including PTA. ${ }^{[27,28]}$ When the patients with facial nerve schwannomas have tumor involving the geniculate region, its diagnosis becomes relatively simple. Intracranial facial nerve schwannomas present the major diagnostic challenge. The CT findings associated with a purely proximal facial nerve schwannoma are identical to those of an acoustic schwannoma. Normal facial function and a PF tumor is unlikely to be due to a facial nerve schwannoma. ${ }^{[29]}$ Fried $^{[22]}$ has stated that intradural facial nerve schwannomas are extremely rare, and histologic studie ${ }^{[30]}$ have shown that the geniculate region is predisposed to the development of facial nerve neoplasms. Radiologic studies of facial nerve schwannoma ${ }^{[31]}$ rarely show an intracranial facial nerve schwannoma without geniculate involvement. Finally, the often-cited study of 600 temporal bones by Saito and Baxte ${ }^{[24]}$ reveals that the "intracranial" facial nerve schwannomas found were all clearly associated with aberrant geniculate ganglion cells in the internal auditory canal. Surgery is the only treatment for facial nerve schwannoma, and therefore, patients are left with permanent facial dysfunction after treatment because tumor removal almost always requires total nerve resection. The best means of reconstructing the facial nerve has been a controversial subject. Spector ${ }^{[32]}$ has stated a preference for short cable grafts over long cable grafts for reconstruction of the facial nerve. Spector also prefers to use a hypoglossal-facial anastomosis instead of long nerve grafts and he also condemns the use of sutureless anastomosis and fibrin glue in nerve repairs. Some are in favor of a nerve interposition graft. There is a trend to poorer recovery in patients with long-standing palsy. ${ }^{[25]}$ Hypoglossal-facial anastomosis also yields good results, particularly in patients with long-standing preoperative facial palsy. ${ }^{[2,33]}$ Those patients with normal facial movements in the presence of an intracranial facial nerve schwannoma may be better served by having radiologic follow-up and deferral of surgery until facial dysfunction or other problems supervene. ${ }^{[29]}$

\section{Glossopharyngeal and vagal nerve schwannoma (JFS)}

Schwannomas arising from the lower cranial nerves (ix-xi) are rare, constituting only $3 \%$ of all intracranial 
schwannomas unassociated with neurofibromatosis. ${ }^{[34]} \mathrm{A}$ great majority of these tumors present as JF lesions and, less commonly, they occur along the extracranial course of these nerves. ${ }^{[34]}$ An intracranial hugely extended lesion is extremely rare. The vagus is affected more commonly than any other nerve. They mainly occur in middle-aged adults and are more common in women than in men. ${ }^{[35]}$ Nerve sheath tumors in the head and neck are a common manifestation of neurofibromatosis. ${ }^{[35]} \mathrm{JF}$ lesions mostly present in the fifth decade of life. They are very rare. The paragangliomas are the most common tumors in this region, followed by schwannomas, meningiomas, metastases, giant cells tumors, chondrosarcomas, plasmocytomas, epidermoid cysts, amyloidomas, and endolymphatic sac tumors, which are also described in this location with primary and expansive lesions. ${ }^{[36]}$ The schwannomas arising from the glossopharyngeal nerve are most common in this region, followed by the vagus, accessory, and more rarely, hypoglossal nerve tumors. ${ }^{[37,38]}$ The tumors at JF area are classified by Kaye et al. into three types. Type A refers to the intracranial origin lesions, with a minimal osseous extension. Type B lesions are the primary ones of the bone with or without intracranial component. Type $\mathrm{C}$ lesions are primarily extracranial with minimal extension into the cranial bone or posterior cavity. Pellet et al. added the so-called type $\mathrm{D}$, which refers to the hour-glass-shaped tumor, that involves the JF, with intracranial and extracranial components. ${ }^{[36,39]}$ The schwannomas are usually solid, circumscribed, and well-delimited, and may cause cystic degeneration or primary cysts. The clinical presentation of the JF tumors depends on their site of origin. The tumor origin, size, and site may be responsible for delayed presentation. ${ }^{[36]}$ The early symptoms of tumors originated in the JF are, in most cases, conductive hearing loss and tinnitus. Other lesions may cause paralysis of the lower cranial pairs as a first symptom. ${ }^{[38]}$ The tumors that expand to the PF usually manifest primarily with deafness, vertigo, and ataxia, which may mimic the clinical presentation of the tumor originating from vestibulocochlear nerve. The JF lesions that expand to extracranial proportions may present with hoarseness, diminishing of the coughing reflex, and reduction of the motor strength of the shoulder girdle, symptoms representing the typical JF syndrome. ${ }^{[37,39,40]}$ It is believed that the diagnosis and nerve origin can be determined by the initial symptoms and the grade of dysfunction of the nerve, especially when compared with adjacent nerves. This connection gives rise to the classic descriptions of the different syndromes affecting the lower cranial nerve, ${ }^{[39-41]}$ including the descriptions by Vernet (involvement of the $9^{\text {th }}, 10^{\text {th }}$, and $11^{\text {th }}$ cranial nerves), Schmidt (the $10^{\text {th }}$ and $11^{\text {th }}$ nerves), Collet-Sicard (the $9^{\text {th }}, 10^{\text {th }}, 11^{\text {th }}$, and $12^{\text {th }}$ nerves), Jackson (the $10^{\text {th }}, 11^{\text {th }}$, and $12^{\text {th }}$ nerves), Tapia (the $10^{\text {th }}, 11^{\text {th }}, 12^{\text {th }}$ nerves, and sympathetic nerve), and Villeret $\left(9^{\text {th }}, 10^{\text {th }}, 12^{\text {th }}\right.$ nerves, and sympathetic nerve), as well as a combination of these syndromes. Rather than corresponding to the nerve of origin, however, the symptoms are marked by their variability in presentation, and some patients have no dysfunction of the lower cranial nerves. Symptoms secondary to increased cranial pressure (blurred vision and headaches) are actually the most common complaints, and the most common and earliest sign is compromise of the eighth cranial nerve complex. This is what makes the differential diagnosis of schwannomas and acoustic tumors difficult. ${ }^{[42]}$ The presence of nystagmus, ataxia, vertigo, pyramidal tract involvement, and other cranial nerve deficits (fifth, sixth, and seventh nerves) has been reported. ${ }^{[41]}$

Neuroimaging indicates the tumor extension, as well as helps differentiate between the schwannomas and other JF tumors such as meningiomas and paragangliomas. On CT scan, there may be enlargement of the JF with well-defined osseous margins. On MRI images, there is hyperintensity in $\mathrm{T} 2$ and hypointensity in $\mathrm{T} 1$ images, with a strong enhancement after gadolinium administration. It may present as a heterogeneous tumor due to the presence of necrosis or cystic formations. ${ }^{[40]}$ Cerebral DSA shows moderate vascularization that differentiates the schwannomas from the paragangliomas of such a region, which are intensely vascularized. ${ }^{[39]}$ Successful treatment of lesions involving the JF includes complete tumor removal without creating additional neurological deficits. Although a mortality rate as high as $16 \%$ had been reported in early surgical series, ${ }^{[43]}$ recent advances in surgical microneuroanatomy, neuroradiology, and microsurgical and skull base techniques have drastically decreased this rate, and no deaths directly related to the surgical procedure have been reported in the latest series. ${ }^{[41,44]}$ The lower cranial nerves must be carefully evaluated because they are the source of major and life-threatening postoperative complications, especially if the patient had no deficits preoperatively. The acute development of postoperative deficits in such patients allows no chance for compensatory mechanisms to develop. ${ }^{[44]}$ Appropriate measures, such as the nothing-by-mouth regimen with parenteral nutrition, swallowing exercises, and soft mechanical diets with swallowing precautions, are taken if the patient exhibits a risk of aspiration on postoperative swallowing studies. Postoperative deficits might improve, but if the risk of aspiration persists or the patient has marked dysphonia, vocal cord medialization is advised.

Complete surgical resection is still a challenge in spite of the development of new advanced operative 
microsurgical techniques applied to the cranial base. The tumor extension to the cavernous sinus, clivus, or brain stem is sometimes a limiting factor to the total removal of the lesion. Multidisciplinary approach is sometimes needed where neurosurgeons, otorhinolaryngologists, and sometimes neuroradiologists work together for a better diagnostic and preoperative assessment, in addition to a better management of these patients. ${ }^{[36-38]}$ Radical removal of benign JF tumors is the treatment of choice, may be curative, and is achieved with low mortality and morbidity rates. Larger lesions can be radically excised in one surgical procedure by using a multidisciplinary approach. Reconstruction of the skull base with vascularized myofascial flaps reduces postoperative CSF leaks. Postoperative lower cranial nerve deficits are the most dangerous complication. ${ }^{[45]}$ The surgical approach should be planned to achieve complete resection, as repeated operation drastically increases the chance of injury to the lower cranial nerves. Intraoperative electrophysiological monitoring of these nerves as well as brainstem auditory evoked potentials are important adjuvants for preventing injury to the lower cranial nerves, the facial nerve, and the vestibulocochlear complex. The choice of surgical approach is of vital importance for success. The tumor's location and extension defines the surgical approach. For tumors confined intracranially (Type A), a retrosigmoid approach provides adequate exposure. ${ }^{[4]}$ For tumors involving the bone window, a wider exposure is required. The choice of the surgical approach implies the surgeon's knowledge and understanding of the micro-anatomy of the region to preserve the neurovascular structures as much as possible. Katsuta et al. ${ }^{[46]}$ split up the JF region into three portions: One nervous (intrajugular) and two venous. The $i x, x, x i$ cranial nerves are in the nervous portion localized between the two venous portions. Finally, it should be considered that there are many anatomical variations in the course of neurovascular structures in this region and that they do not always respect and conform to the compartmentalization into different portions (pars nervosa and pars venosa). ${ }^{[40]}$ The complexity and the large range of anatomical variations of such a region require careful clinical and neurological examination should be realized. CT, MRI, and magnetic resonance angiography (MRA) are highly recommended. In cases of suspected much vascularized lesions, DSA should be done to explore the vascular network and contemplate embolization. Sometimes, internal carotid artery is involved and invaded, so that a balloon occlusion test is useful. Even if many and different approaches ${ }^{[47]}$ exist to manage such lesions either with intracranial and/or extracranial extensions, some believe that the juxtacondylar approach provides an optimal and safe exposure to the JF with a limited drilling of petrous bone and mastoid, thus significantly reducing the risk of auditory loss, facial nerve palsy, and CSF leak. Actually, this approach provides an inferior and posterior access to the JF being mainly based on the vertebral artery control so giving also the chance of dividing the tumor blood supply. The tumor location and extension generally defines the best surgical approach; for tumors confined intracranially (type I), a retrosigmoid approach may provide an adequate exposure; $;^{[48]}$ for foraminal and extracranial tumors, a more extensive exposure is necessary, but preferably the labyrinth should not be sacrificed ${ }^{[49]}$ as hearing improvements have been already reported in many occasions. ${ }^{[48]}$ Kadri and Al-Meft, ${ }^{[50]}$ describing a series of six dumbbell JFSs, reported that the tumor was completely resected in all patients with no additional cranial nerve deficits and that with a mean follow-up of 32.8 months, two of the six patients with preoperative IX and $X$ cranial nerve palsy attained significant improvement and two of four patients with preoperative hypoglossal nerve palsy completely recovered mobility of the tongue. In the same series, one of the two patients with hearing loss had significant improvement of that deficit, and a patient with facial palsy had the nerve function completely restored. A patient with a sixth cranial nerve deficit got the ocular motion completely restored. Samii et al., ${ }^{[48]}$ reporting on a series of $16 \mathrm{JFS}$ s of whom five were type IE, described that in the immediate postoperative period, the temporary cranial nerve morbidity rate was $38 \%$. Three patients experienced facial palsy, one abducent palsy, one swallowing problems, and another one had tongue weakness as new deficits; in the other patients, the cranial nerve dysfunction remained as it was preoperatively, and with a mean follow-up of 22 months, all cranial nerve dysfunctions improved considerably. The experience with radiosurgical treatment of JFSs is still limited. ${ }^{[51,52]}$ In the largest reported series, Muthukumar et al. ${ }^{[52]}$ concluded that this treatment should be reserved for patients with small tumors and intact lower cranial nerves. In one of our cases with a huge tumor from intracranial level to neck at the level of common carotid bifurcation, we did not go for extensive facial nerve mobilization and external or middle ear disruption as the tumor itself gave the space between the sigmoid sinus and facial nerve for its removal below the JF and the rest of the tumor was removed at neck level below the facial nerve. For effective closure of JF and tumor dead space, we close the JF by two sheets of facia lata and fat.

\section{Accessory nerve schwannoma}

Schwannomas of accessory nerve represent a rare form of all cranial nerve schwannomas. These tumors are defined as arising specifically from or encasing cranial 
nerve XI. The extent of cranial nerve involvement may include the cisternal, foraminal, and extracranial segments of the spinal accessory nerve and the extracranial form is the least common one. ${ }^{[33]}$ The characteristic clinical finding is denervation atrophy of the trapezius and sternocleidomastoid muscles. ${ }^{[54]}$ Of the remaining lower cranial nerves, cranial nerve VIII is most often compromised and cranial nerve XII is infrequently affected. ${ }^{[55]}$ Hypoglossal nerve dysfunction tends to occur with large intraforaminal masses. When there is a prominent intracranial component of tumor, signs and symptoms referable to brain stem and cerebellar dysfunction may be found. ${ }^{[5]}$ MRI with contrast is the technique of choice for imaging these types of schwannomas. The CT and MR appearance of cranial nerve XI schwannomas parallels that of cranial nerve VIII schwannomas. On CT, these tumors are hypointense or isodense relative to brain parenchyma. They may contain cystic or necrotic foci, but do not manifest a calcified component. ${ }^{[56]}$ Surgery is the treatment of choice, but an already nonfunctioning nerve usually does not recover.

\section{Hypoglossal nerve schwannoma}

The first case of hypoglossal neurinoma was reported in 1933. ${ }^{[57]}$ The leading symptoms of the hypoglossal neurinoma include headache and dizziness. ${ }^{[58]}$ High-resolution CT scan of the PF with bony details of the foramen passing through by the cranial nerve is the neurodiagnostic procedure of choice. ${ }^{[58]}$ The cystic spaces can result in high signal intensity on T2-weighted MRIs. ${ }^{[59]}$ The hypoglossal nerve arises from the hypoglossal nucleus and then passes through the hypoglossal canal, and provides motor fibers innervating the muscles of the tongue. ${ }^{[60]}$ Most of the hypoglossal neurinomas have a dumbbell shape and involve both intracranial and extracranial segments of the hypoglossal nerve.${ }^{[6]]}$ However, intracranial hypoglossal neurinomas are unusual. ${ }^{[62]}$ The most distinguishing clinical findings of patients with hypoglossal nerve schwannoma are unilateral tongue atrophy and fasciculations. ${ }^{[5]}$ Hypoglossal schwannoma may present without preoperative hypoglossal nerve palsy. ${ }^{[63]}$ The differential diagnosis of tumor involving hypoglossal canal includes chemodectoma, chordoma, meningioma, lymphoma, and metastatic tumors. ${ }^{[64]}$ Since schwannomas are benign tumors, the goal of the treatment is complete surgical removal. Their locations in a complex region of the skull base can make confirmation of its origins difficult due to the intimate anatomical relationship to neurovascular and brain stem structure. ${ }^{[65]}$ The far lateral transcondylar approach, far lateral transcondylartranstubercular, extreme far lateral approach with or without stabilization, and fusion of condylar joint may be required for surgical excision of these tumor. Surgical approach to the posterior skull base and craniovertebral junction is often a complex and lengthy procedure associated with significant morbidity. Respiratory complications account for the high postoperative mortality (40\%) reported in the early literature and were seen most frequently in patients who had exhibited preoperative $12^{\text {th }}$ and $10^{\text {th }}$ cranial nerve dysfunction. ${ }^{[66]}$

Although there have been reports of malignant trigeminal neuromas, none of the patients in our series had a malignant neurinoma.

\section{Conclusion}

Nonvestibular schwannomas are far less common than vestibular schwannomas, but all are curable benign lesions. Surgical approach to the skull base and craniovertebral junction is often a complex and lengthy procedure associated with chances of significant morbidity. Moreover, repeated operation drastically increases the chance of injury to the lower cranial nerves. But early diagnosis, proper investigations, and evaluation, along with appropriate decision making and surgical planning with microsurgical techniques are the essential factors that can result in an optimum outcome with complete resection and no new neurological deficit in nonvestibular schwannomas.

\section{References}

1. Acharya R, Husain S, Chhabra SS, Patir R, Bhalla S, Seghal AD. Sixth nerve schwannoma: A case report and literature review. Neurol Sci 2003;24:74-9.

2. Kim DS, Choi JU, Yang KH, Jung JM. Optic sheath schwannoma: Report of two cases. Childs Nerv Syst 2002;18:684-9.

3. Vachata P, Sames M. Abducens nerve schwannoma mimicking intrinsic brainstem tumor. Acta Neurochir (Wien) 1991;151:1281-7.

4. Ginsberg F, Peyster RG, Rose WS, Drapkin AJ. Sixth nerves schwannoma: MR and CT demonstration. J Comput Assist Tomogr 1998;12:482-4.

5. Okura A, Shigemori M, Abe T, Yamashita M, Kojima K, Noguchi S. Hemiatrophy of the tongue due to hypoglossal schwannoma shown by MRI. Neuroradiology 1994;36:239-40.

6. Saetia K, Larbcharoensub N, Wetchagama N. Oculomotor nerve schwannoma: A case report and review of the literature. J Med Assoc Thai 2011;94:1002-7.

7. Gentry LR, Mehta RC, Appen RE, Weinstein JM. MR imaging of primary trochlear nerve neoplasms. AJNR Am J Neuroradiol 1991;12:707-13.

8. Kovacs W. Ueber ein solitares neurinom des nervus oculomotorius. Zentralbl Allg Pathol 1927;40:518-22.

9. Katoh M, Kawamoto T, Ohnishi K, Sawamura Y, Abe H. Asymptomatic schwannoma of the oculomotor nerve: Case report. J Clin Neurosci 2000;7:458-60.

10. Kurokawa Y, Uede T, Honda O, Honmou O. Successful removal of intracavernous neurinoma originating from the oculomotor nerve--case report. Neurol Med Chir (Tokyo) 1992;32:225-8.

11. Netuka D, Benes V. Oculomotor nerve schwannoma. Br J Neurosurg 2003;17:168-73.

12. Shenoy SN, Raja A. Cystic trochlear nerve neurinoma mimicking intrinsic brainstem tumour. Br J Neurosurg 2004;18:183-6. 
13. Celli P, Ferrante L, Acqui M, Mastronardi L, Fortuna A, Palma L. Neurinoma of the third, fourth, and sixth cranial nerves: A survey and report of a new fourth nerve case. Surg Neurol 1992;38:216-24.

14. Gerganov V, Amir S, Koerbel A, Brandes A, Stan A, Madjid S. Cystic trochlear nerve schwannoma. Case report. Surg Neurol 2007;68:221-5.

15. Bhatjiwale MG, Nadkarni TD, Desai KI, Goel A. Pathological laughter as a presenting symptom of massive trigeminal neuromas: Report of four cases. Neurosurgery 2000;47:469-72.

16. Day JD, Fukushima T. The surgical management of trigeminal neuromas. Neurosurgery 1998;42:233-41.

17. Konovalov AN, Spallone A, Mukhamedjanov DJ, Tcherekajev VA, Makhmudov UB. Trigeminal neurinomas. A series of 111 surgical cases from a single institution. Acta Neurochir (Wien) 1996;138:1027-35.

18. Goel A, Muzumdar D, Raman C. Trigeminal neuroma: Analysis of surgical experience with 73 cases. Neurosurgery 2003;52:783-90.

19. Goel A, Nadkarni T. Basal lateral subtemporal approach for trigeminal neurinomas: Report of an experience with 18 cases. Acta Neurochir (Wien) 1999;141:711-9.

20. Dolenc VV. Anatomy and Surgery of the Cavernous Sinus. Vienna: Springer-Verlag; 1989. p. 269-338.

21. Goel A. Infratemporal fossa interdural approach for trigeminal neurinomas. Acta Neurochir (Wien) 1995;136:99-102.

22. Friede RL. Pathology of intracranial tumors producing facial palsy. In: Fisch U, editor. Facial Nerve Surgery. Birmingham, AL: Aesculapius Publishing; 1977. p. 470-3.

23. Tung H, Chen T, Weiss MH. Sixth nerve schwannomas. Report of two cases. J Neurosurg 1991;75:683-41.

24. Conley J, Janecka I. Schwann cell tumors of the facial nerve. Laryngoscope 1974;84:958-62.

25. Lipkin AF, Coker NJ, Jenkins HA, Alford BR. Intracranial and intratemporal facial neuroma. Otolaryngol Head Neck Surg 1987;96:71-9.

26. O'Donoghue GM, Brackmann DE, House JW, Jackler RK. Neuromas of the facial nerve. Am J Otol 1989;10:49-54.

27. Pulec JL. Facial nerve neuroma. Laryngoscope 1972;82:1160-76.

28. Pillsbury HC, Price HC, Gardiner LJ. Primary tumors of the facial nerve: Diagnosis and management. Laryngoscope 1983;93:1045-8.

29. Dort JC, Fisch U. Facial nerve schwannomas. Skull Base Surg 1991;1:51-6.

30. Fisch U, Ruttner J. Pathology of intratemporal tumors involving the facial nerve. In: Fisch U, editor. Facial Nerve Surgery: Proceedings of the Third International Symposium. Birmingham, AL: Aesculapius Publishing; 1977. p. 448-56.

31. Burres S, Fisch U. The comparison of facial grading systems. Arch Otolaryngol Head Neck Surg 1986;112:755-8.

32. Spector JG. Mimetic surgery for the paralyzed face. Laryngoscope 1985;95:1494-522.

33. Conley J, Baker DC. Hypoglossal-facial anastomosis for reinnervation of the paralyzed face. Plast Reconstr Surg 1979;63:63-72

34. Sharma RR, Pawar SJ, Dev E, Chackochan EK, Suri N. Vagal schwannoma of the cerebello-medullary cistern presenting with hoarseness and intractable tinnitus: A rare case of intra-operative bradycardia and cardiac asystole. J Clin Neurosci 2001;8:577-80.

35. Kim Y, Ko Y, Yi H, Oh S. A case of hypoglossal neurilemmoma resected via Burr-hole craniectomy. J Korean Neurosurg Soc 2007;41:43-6.

36. Tavares JR, Sampaio AL, Ferreira DB, Cavalheiro JB, Araújo MF, Oliveira AC. Jugular foramen schwannoma: Case report. Arq Int Otorrinolaringol 2009;13:99-103.

37. Mattos JP, Ramina R, Borges W, Ghizoni E, Fernandes YB, Paschoal JR, et al. Intradural jugular foramen tumors. Arq Neuropsiquiatr 2004;62:997-1003.

38. Ramina R, Maniglia JJ, Fernandes YB, Paschoal JR, Pfeilsticker LN, Coelho Neto M. Tumors of the jugular foramen: Diagnosis and management. Neurosurgery 2005;57 Suppl 1:59-68.

39. Sarma S, Sekhar NL, Schessel DA. Nonvestibular schwannomas of the brain: A 7-year experience. Neurosurgery 2002;50:437-48.

40. Eldevik OP, Gabrielsen TO, Jacobsen EA. Imaging findings in schwannomas of the jugular foramen. AJNR Am J Neuroradiol 2000;21:1139-44.

41. Gómez Beldarrain M, Fernández Cantón G, García-Moncó JC. Hypoglossal schwannoma: An uncommon cause of twelfth-nerve palsy. Neurologia 2000;15:182-3.
42. Arenberg IK, McCreary HS. Neurilemmoma of the jugular foramen. Laryngoscope 1971;81:544-57.

43. Pluchino F, Crivelli G, Vaghi MA. Intracranial neurinomas of the nerves of the jugular foramen. Report of 12 personal cases. Acta Neurochir (Wien) 1975;31:201-21.

44. Samii M, Migliori M, Tatagiba M, Babu R. Surgical treatment of trigeminal schwannomas. J Neurosurg 1995;82:711-8.

45. Ramina R, Maniglia JJ, Fernandes YB, Paschoal JR, Pfeilsticker LN, Neto MC, et al. Jugular foramen tumors: Diagnosis and treatment Neurosurg Focus 2004;17:E5

46. Katsuta T, Rhoton AL Jr, Matsushima T. The jugular foramen: Microsurgical anatomy and operative approaches. Neurosurgery 1997;41:149-202.

47. Kawahara N, Sasaki T, Nibu K, Sugasawa M, Ichimura K, Nakatsuka T, et al. Dumbbell type jugular foramen meningioma extending both into the posterior cranial fossa and into the parapharyngeal space: Report of 2 cases with vascular reconstruction. Acta Neurochir (Wien) 1998;140:323-31.

48. Samii M, Babu RP, Tatagiba M, Sepehrnia A. Surgical treatment of jugular foramen schwannomas. J Neurosurg 1995;82:924-32.

49. Vellutini EA, Cruz OL, Velasco OP, Miniti A, Almeida GM. Reversible hearing loss from cerebellopontine angle tumors. Neurosurgery 1991;28:310-3.

50. Kadri PA, Al-Mefty O. Surgical treatment of dumbbell-shaped jugular foramen schwannomas. Neurosurg Focus 2004;17:E9.

51. Megerian CA, McKenna MJ, Nadol JB Jr. Non-paraganglioma jugular foramen lesions masquerading as glomus jugulare tumors. Am J Otol 1995;16:94-8.

52. Muthukumar N, Kondziolka D, Lunsford LD, Flickinger JC. Stereotactic radiosurgery for jugular foramen schwannomas. Surg Neurol 1999;52:172-9.

53. Nakashima T, Tomita K, Uemura T, Matsushima T, Fukui M. Accessory nerve schwannoma extending extracranially to the second cervical level of vertebra. J Laryngol Otol 1998;102:959-61.

54. Noyek AM, Chapnik JS, Wortzman G, Kandel R. Schwannoma of the intrasternomastoid portion of the spinal accessory nerve: Sophisticated pre-operative MRI diagnosis and appropriate surgical management. J Otolaryngol 1992;21:286-9.

55. Gómez Beldarrain M, Fernández Cantón G, García-Moncó JC Hypoglossal schwannoma: An uncommon cause of twelfth-nerve palsy. Neurologia 2000;15:182-3.

56. Bilaniuk LT. Adult infratentorial tumors. Semin Roentgenol 1990;25:155-73.

57. De Martel T, Subirana, Guillaume J. Los tumors de la fosa cerebral posterior: Voluminoso neurinoma del hipogloso con desarrelle juxtabulbo-protuberencial. Operacion-cura-cion. Ars Med 1933;9:416-9.

58. Fujiwara S, Hachisuga S, Numaguchi Y. Intracranial hypoglossal neurinoma: Report of a case. Neuroradiology 1980;20:87-90.

59. Badion ML, Lim CC, Teo J, Ong PL, Hui F. Solitary fibrous tumor of the hypoglossal nerve. AJNR Am J Neuroradiol 2003;24:343-5.

60. Thomposn EO, Smoker WR. Hypoglossal nerve palsy: A segmental approach. Radiographics 1994;14:939-58.

61. Jia G, Wang Z, Zhang J. Diagnosis and treatment of hypoglossal neurinoma. Zhonghua Yi Xue Za Zhi 2001;81:1264-5.

62. Rachinger J, Fellner FA, Trenkler J. Dumbbell-shaped hypoglossal schwannoma. A case report. Magn Reson Imaging 2003;21:155-8.

63. Lee DY, Lee SH, Yoo H, Jung HW, Han DH, Cho BK. Hypoglossal neurinoma without preoperative hypoglossal nerve palsy-Report of 2 cases. J Korean Neurosurg Soc 1999;28:1800-4.

64. Bartal AD, Djaldetti MM, Mandel EM, Lerner MA. Dumb-bell neurinoma of the hypoglossal nerve. J Neurol Neurosurg Psychiatry 1973;36:592-5.

65. Lister JR, Rhoton AL Jr, Matsushima T, Peace DA. Microsurgical anatomy of the posterior inferior cerebellar artery. Neurosurgery 1982;10:170-99.

66. Scott M, Wycis HT. Intracranial neurinoma of the hypoglossal nerve; successful removal; case report. J Neurosurg 1949;6:333-6.

How to cite this article: Chowdhury FH, Haque MR, Kawsar KA, Sarker MH, Hasan M, Goel AH. Intracranial nonvestibular neurinomas: Young neurosurgeons' experience. J Neurosci Rural Pract 2014;5:231-43.

Source of Support: Nil. Conflict of Interest: None declared. 